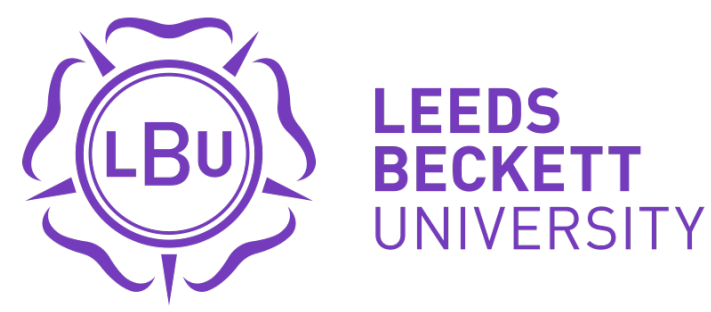

Citation:

Jackson, J and Williams, TL and McEachern, B and Latimer-Cheung, A and Tomasone, J (2019) Fostering quality experiences: Qualitative perspectives from program members and providers in a community-based exercise program for adults with physical disabilities. Disability and Health Journal, 12 (2). pp. 296-301. ISSN 1876-7583 DOI: https://doi.org/10.1016/j.dhjo.2018.11.008

Link to Leeds Beckett Repository record:

https://eprints.leedsbeckett.ac.uk/id/eprint/5445/

Document Version:

Article (Accepted Version)

Creative Commons: Attribution-Noncommercial-No Derivative Works 4.0

The aim of the Leeds Beckett Repository is to provide open access to our research, as required by funder policies and permitted by publishers and copyright law.

The Leeds Beckett repository holds a wide range of publications, each of which has been checked for copyright and the relevant embargo period has been applied by the Research Services team.

We operate on a standard take-down policy. If you are the author or publisher of an output and you would like it removed from the repository, please contact us and we will investigate on a case-by-case basis.

Each thesis in the repository has been cleared where necessary by the author for third party copyright. If you would like a thesis to be removed from the repository or believe there is an issue with copyright, please contact us on openaccess@leedsbeckett.ac.uk and we will investigate on a case-by-case basis. 
FOSTERING QUALITY EXPERIENCES

Fostering quality experiences: Qualitative perspectives from program members and providers in a community-based exercise program for adults with physical disabilities

Julia Jackson, BScH ${ }^{1}$, Toni L. Williams, $\mathrm{PhD}^{2}$, Brittany M. McEachern, MScPT ${ }^{1}$, Amy E. Latimer-Cheung, $\mathrm{PhD}^{1} \&$ Jennifer R. Tomasone, $\mathrm{PhD}^{1 *}$

${ }^{1}$ School of Kinesiology and Health Studies, Queen's University

${ }^{2}$ Institute for Sport, Physical Activity and Leisure, Leeds Beckett University, UK

*Corresponding author: Jennifer R. Tomasone

28 Division Street, KHS 301F

Kingston, Ontario, Canada, K7L3N6

$+01-613-533-6000$ ext 79193

tomasone@queensu.ca

Key words: Community-based; Exercise program; Physical disability; Quality participation

Conflicts of interest: AELC and JRT are Co-Directors of Revved Up, and JJ and BMM were former volunteers at Revved Up. TW declares no conflicts of interest. No financial support was received to conduct this study.

Submission Declaration: The manuscript has not been published and will not be submitted elsewhere for publication while being considered by Disability Health Journal. The current study was presented at the $6^{\text {th }}$ International Conference on Qualitative Research in Sport and Exercise in Vancouver, Canada (June 2018).

\section{Word counts:}

Abstract: 234

Complete manuscript: 4170

Number of references: 21

Number of figures/tables: 1 


\title{
FOSTERING QUALITY EXPERIENCES
}

\begin{abstract}
Background: Opportunities to be physically active within one's community need to be available and accessible to individuals with physical disabilities in order to increase participation; however, what constitutes quality participation within these opportunities and how exercise programs can foster quality experiences for this population have yet to be explored.
\end{abstract}

Objectives: (1) To explore the participation experiences of adults with physical disabilities in a community-based exercise program from two perspectives; (2) To establish whether the participants' experiences could be understood through an existing quality participation framework.

Methods: Participants were thirteen members and ten providers (i.e., coordinators, trainers, and supervisors) recruited from a community-based exercise program for adults with physical disabilities. Six focus groups (three with program members and three with each distinct group of program providers) were carried out, audio recorded and transcribed. Following an initial inductive thematic analysis, themes were deductively mapped to Martin Ginis and colleagues' (2017) conceptualization of the experiential aspects of participation. Results: Six themes (autonomy, belongingness, challenge, engagement, mastery and meaning) important for experiencing quality participation were identified and were in line with Martin Ginis and colleagues' (2017) framework.

Conclusion: Findings support the use of Martin Ginis and colleagues' (2017) conceptualization of quality participation within the context of community-based exercise programs for adults with physical disabilities. Practitioners and researchers can use the findings as a starting point for designing, implementing and evaluating programs with the goal of optimizing quality participation. 


\section{FOSTERING QUALITY EXPERIENCES}

\section{Introduction}

Participation, defined as involvement in life situations ${ }^{1}$, is a key concept to consider when promoting physical activity (PA; i.e., sport and exercise) for individuals with disabilities $^{2,3}$. Full and effective participation in society - including participation in recreation, leisure and sport activities - is a basic human right ${ }^{4}$. However, individuals with disabilities do not participate in PA on an equal basis with the general population. Rates of inactivity among Canadians with a disability, for example, are higher than rates among people without a disability ${ }^{5,6}$. Further, people with disabilities face unique barriers to participation in PA, such as a lack of accessible equipment, facilities and transportation ${ }^{7}$. Community-based exercise programs that are available and accessible may increase PA participation, health and quality of life among this population ${ }^{8,9,10}$.

When promoting participation for individuals with disabilities, there are two key aspects to consider: quantity and quality of participation ${ }^{11,12}$. Most often, participation is described and promoted quantitatively as the number of people participating and how much or how often they participate ${ }^{13}$. However, participation extends beyond objectively being present to one's subjective experiences while participating ${ }^{12,13}$. Several participation frameworks outline what constitutes quality participation experiences in the context of occupational therapy for individuals with disabilities ${ }^{13}$. Following a systematic, configurative review of these frameworks, Martin Ginis and colleagues proposed a consolidated conceptualization of quality participation that can be applied in a PA context ${ }^{13}$. Martin Ginis and colleagues ${ }^{13}$ framework encompasses six experiential aspects of participation: autonomy (having independence, choice and control), belongingness (experiencing a sense of belonging to a group; acceptance/respect from others; included at the interpersonal or societal levels), challenge (feeling appropriately challenged), engagement (engaged in the activity, motivated, focused, involved; experiencing flow), mastery (experiencing achievement/competence/sense 


\section{FOSTERING QUALITY EXPERIENCES}

of accomplishment; self-efficacy) and meaning (contributing toward obtaining a personal or socially meaningful goal; feeling a sense of responsibility to others). These experiential aspects of participation may be important for optimizing PA experiences; however, research examining perspectives of quality PA experiences for persons with a disability is in its infancy.

Studies among military veterans ${ }^{11}$ and parasport athletes ${ }^{14}$ with physical disabilities found the experiential aspects of participation to be important for quality participation experiences in various PA settings. However, subjective aspects of participation may differ depending on the population and context ${ }^{15}$; that is, the experiences of community-dwelling adults with physical disabilities in an exercise setting may differ from veterans or parasport athletes in sport settings. For instance, within a community context, an individual's motivation for participation may be to maintain functional capacity, in contrast to other PA contexts where participants may be working towards achieving a certain performance outcome (i.e., competing at the Invictus or Paralympic Games). Some preliminary research examining participation experiences in community-based exercise settings exists. Adam and Morgan ${ }^{10}$ explored the goals and benefits of participating in such programs and found that community participation (i.e., increased independence for activities of daily living in the home and community) was an important outcome for individuals with disabilities; however, their study was not focused on the mechanisms, or how to foster quality experiences to achieve such outcomes. Similarly, evidence from a systematic review about communitybased exercise programs shows that the group context (i.e., participating with peers) and leadership context (i.e., having knowledgeable instructors) are important for fostering aspects of quality participation among adults with physical disabilities; however, few studies identified mechanisms by which quality experiences may be fostered within exercise programs for this population ${ }^{2}$. Examining how to foster experiential aspects of participation 


\section{FOSTERING QUALITY EXPERIENCES}

in an existing community-based exercise program from the perspectives of both program providers and program members would offer a richer understanding of how quality experiences in such programs are implemented and received, respectively, as well as help fill an existing gap in the literature ${ }^{16}$.

Accordingly, the purposes of this study were to (1) explore the participation experiences of adults with physical disabilities in a community-based exercise program from two perspectives, and (2) establish whether participants' experiences could be understood through Martin Ginis and colleagues' ${ }^{13}$ quality participation framework. An understanding of participation experiences within community-based exercise programs from the perspectives of both program members and program providers will improve practitioners' ability to design and implement programs that optimize full participation, as well as researchers' ability to evaluate the mechanisms by which program components may foster quality experiences, among persons with physical disabilities. 


\section{FOSTERING QUALITY EXPERIENCES}

\section{Methods}

Study design

A qualitative methodology was drawn upon for this study as this approach focuses upon how people interpret and make sense of their experiences ${ }^{17}$ and has been previously recommended for the exploration of quality participation experiences ${ }^{13}$. Furthermore, this study was underpinned by interpretivism and framed by ontological relativism (i.e,, psychosocial reality is perceived as multiple, subjective and mind-dependent) and epistemological constructionism (i.e., knowledge is constructed through relational interactions ${ }^{17}$ ). It is important to understand the philosophical roots of any method of inquiry as they challenge the position the researchers take as to what is studied, what counts as knowledge, and how the results are interpreted The researchers in this study included two researchers (ALC, JT) with expertise in physical activity promotion for adults with physical disabilities who direct the exercise program, two students with volunteer experience in the exercise program (JJ, BM) and qualitative methodologist (TW) who was independent of the exercise program. We have demonstrated the application of our philosophical framework by detailing the process of data collection and analysis and highlighting appropriate criteria that may be used to judge the quality of this research.

\section{Exercise program}

Revved up is an existing community-based exercise program for adults with various physical disabilities (e.g., spinal cord injury [SCI] and multiple sclerosis [MS]). Program members attend two 60-minute exercise sessions per week at two gyms with adapted equipment. The exercise sessions are individualized to each program member's needs and ability and include both strength and aerobic training components.

Four groups of program providers are involved in Revved Up. The program coordinator oversees all aspects of the program from administrative tasks to volunteer 


\section{FOSTERING QUALITY EXPERIENCES}

recruitment. Program trainers have a professional certification (e.g., Canadian Society of Exercise Physiology) and are responsible for the development of individualised exercise plans for members. Program supervisors are trained health studies, physical education and kinesiology students responsible for overseeing volunteers and members. Supervisors have all served as program volunteers. Lastly, program volunteers are primarily undergraduate health studies, physical education and kinesiology students who work one-on-one with members and assist with setting up exercise equipment, and monitoring members' exercise technique and progress.

\section{Participants}

Following institutional research ethics board approval, a criterion-based purposive sampling strategy ${ }^{17}$ was used to recruit program members and providers. Program members were recruited during exercise sessions by two methods: 1) advertisements placed at the two gym locations and 2) handouts inserted into members' exercise plans. Providers with a role in program implementation (e.g., coordinators, trainers and supervisors) were recruited by email. In total, 13 members and 10 providers volunteered to participate.

\section{Data collection}

Focus groups were selected for data collection over individual interviews as this method stimulates talk through interaction among participants and can explore shared perspectives of a topic ${ }^{17}$. The focus group semi-structured guide was designed to gather participants' experiences of the Revved Up program. In line with the study purpose, and the literature on quality participation $\left({ }^{11},{ }^{13},{ }^{15},{ }^{16}\right)$, specific questions were also included to gain participants' perspectives about how to optimize programming and improve quality participation. Questions were iteratively revised following feedback from co-authors (BM, ALC, JT) and other researchers with expertise in disability, PA and quality participation. This process involved changing the wording of the questions to avoid academic jargon and ensure 


\section{FOSTERING QUALITY EXPERIENCES}

open-ended questions. Two different focus group guides were produced. The focus group guide for program members included questions such as "Why do you participate in Revved Up?". The questions differed for program providers depending on their role within Revved Up and included questions such as "Reflecting upon your experience of Revved Up, what components of the program would you keep the same?"

At the start of each focus group, the nature of the project was explained, informed consent was obtained, and all participants completed a demographic questionnaire. Six focus groups were conducted and moderated by the first author who had previously volunteered with the program. Three focus groups were carried out with program members and three focus groups were carried out with program providers. The focus group interviews lasted between 30-60 minutes and were audio-recorded and transcribed verbatim.

\section{Data analysis}

To identify and interpret patterns of meaning across the different data sets in line with the research question, a thematic analysis ${ }^{18}$ was conducted by the first author (JJ). The first phase of the thematic analysis involved a period of familiarization. Practically this consisted of re-reading interview transcripts and making notes about points of interest. Analytically this phase included looking for ideas and concepts that addressed the research question ${ }^{18}$. The second phase involved the systematic process of generating codes to identify key features and points of interest within the data. The transcripts were imported into NVivo for coding and to assist in data organisation ${ }^{18}$. In the third phase, the extracted codes were collapsed into potential candidate themes. Initially, an inductive approach was utilized, and the codes were organized into themes which indicated recommendations for program enhancement.

Upon further analysis and reflection of the data, a number of these recommendations aligned with the aspects of quality participation outlined by Martin Ginis and colleagues ${ }^{13}$. Therefore, in the fourth phase, a deductive approach was taken where the codes and themes 


\section{FOSTERING QUALITY EXPERIENCES}

were refined based upon these six aspects of quality participation. For example, recommendations such as individualized programs and goal setting aligned with 'autonomy'. Furthermore, themes of acceptance, togetherness and relatedness were conceptualized as 'belongingness'. Codes and themes were cross-referenced across all transcripts to ensure the revised deductive thematic map captured the meanings across the whole data set ${ }^{18}$. It was during this phase that concepts in addition to the six aspects of quality participation - such as enjoyment - were re-examined (i.e., is enjoyment related to, or an outcome of, other aspects of participation rather than a separate aspect). The fifth phase involved defining the themes to identify how each theme fits into the broader overall 'story' that is to be told about the data in relation to the research question ${ }^{17}$.

To enhance the quality of this study, a relativist approach was adopted whereby appropriate criteria were drawn upon to guide the research process ${ }^{19}$. For instance, rich rigor was sought by seeking a sample appropriate for the purpose of the study to generate data that could provide meaningful and significant claims. Three authors, two previously involved with Revved Up (BM, JT) and one independent of Revved Up (TW), also acted as 'critical friends' by independently scrutinizing the audit trail in terms of both data collection and theoretical matters to encourage reflection and exploration of alternative interpretations ${ }^{17}$.

\section{Results}

Program members were predominantly male $(n=11 / 13)$ with a mean age of $55.0 \pm 13.7$ years, a range in length of program involvement ( 2 months to 9 years), and a range of mobility impairments (e.g., MS, stroke and amyotrophic lateral sclerosis). Program providers were mostly female $(n=7 / 10)$ between 21 and 33 years of age, and had been involved in the program for 6 months to 4 years.

Six interrelated themes aligning with Martin Ginis and colleagues ${ }^{13}$ conceptualization of quality participation were identified from the experiences of both program members and program providers. There was a high degree of interaction between 


\section{FOSTERING QUALITY EXPERIENCES}

aspects of quality participation. However, for ease of representation, themes are illustrated as separate entities in the results section and the relationships between themes are explored in the subsequent discussion.

\section{Autonomy}

Autonomy was an important theme that was developed through program members having a sense of control over their participation at Revved Up. For example, members were able to set their own exercise goals and choose specific exercises within their individualized plan. Members also valued being able to choose whether or not they worked with program volunteers. Both program members and providers emphasized the importance of volunteers to the successful operation of Revved Up; yet, members also highlighted that doing as much of the exercise program on their own without assistance was important to their sense of independence:

I think that it [the one-on-one] is great. It really works for me, because I used to always use the person who helped volunteer for me. They would get everything. And now I pretty much do everything myself, which is fine like I actually like working by myself. It's been a bit of therapy in itself, working by myself. It's getting a feeling back of, you know, I can do this by myself. I can do it independent[ly]. (Member 2)

\section{Belongingness}

A sense of belongingness was a highly valued aspect of participation in the Revved Up program. Both program members and providers commented on how the social structure facilitated participation. For instance, members appreciated the one-on-one partnerships with volunteers and the respectful attitudes of providers. Furthermore, exercising alongside others with physical disabilities provided peer support, encouragement and enjoyment among program members: 'It's fun because everyone is here and they're all here to enjoy 


\section{FOSTERING QUALITY EXPERIENCES}

themselves." (Member 2). This comradery among program members and feeling a sense of belonging to the group was central to participation:

Like these fellows are saying here, the comradery of this group is $50 \%$ of what we come for. The exercises help no question of that, it keeps our mobility moving, but the second side of that is the comradery, the group action. A togetherness is a big plus. (Member 1)

\section{Challenge}

Program members expressed a need to feel appropriately challenged in terms of the level of difficultly of the exercises. To facilitate a sense of physical challenge, members monitored their progress and asked for exercises to be adjusted accordingly: "Now I improve with each time. I am improving so it gets easier, [I would like it to be] harder next time. A little bit harder." (Member 4). Yet it was the responsibility of program trainers to guide members' exercise progression to ensure the exercises were safe and would confer the greatest benefit:

I just don't like to hear that participants are like, “oh yeah no, I only ever use five pounds or, oh yeah no, I only ever do 20 pounds" [...] You need an expert on the ground to help them. (Trainer 1)

\section{Engagement}

Many aspects of the program kept members engaged in the exercises. For example, members claimed that focusing on their own abilities and performance facilitated engagement. Yet it was perceived from providers that the social aspect of the program motivated long-term participation for some members: "I've seen a lot of social benefits... with the participants forming really great relationships with their volunteers and looking forward to coming back and asking if they can come to more sessions." (Supervisor 4). The 


\section{FOSTERING QUALITY EXPERIENCES}

positive energy, encouragement and support provided by the volunteers were vital in engaging members in the sessions:

Working with the volunteers has been really, really positive because they're very passionate about what they do, they have lots of good energy and so I always feel really [good] and so my mental outlook has certainly been affected even by the volunteers' outlook because [of what] they bring to the table. It's always fun like I'm sure you saw me up there like chatting with them and everything. It's always [a] really good exchange. (Member 13)

\section{Mastery}

A sense of exercise mastery was a vital component of participation in Revved Up. For members, a sense of accomplishment was experienced through improvements in exercise skill and overall functional ability:

I have come a long way from a wheelchair to a walker and I hope to be in a cane in a couple of months... I do my exercises in a standing position now and it's all good, like I said, every week there is a chance for you to improve. I'm riding the bicycle, I never thought I would be able to ride the bicycle... so it's great. (Member 10).

Providers also expressed the importance of giving members the opportunity to progress and experience personal achievements and competence:

And they can see the growth themselves. They say oh it was so hard I couldn't do 3 sets of 10 [repetitions] at the start but in the 3 months I'm doing 3 sets of 10 [repetitions] and then in 2 more months we are going to put the weight up... I think it's so awesome because so many people don't necessarily get that opportunity to watch that for themselves and to see their own progress. (Trainer 1)

\section{Meaning}




\section{FOSTERING QUALITY EXPERIENCES}

Participation in Revved Up was personally meaningful for both program members and providers. Members referred to the importance of exercise at Revved Up for their health. They felt the improvements in health and physical fitness positively impacted their quality of life; participation enabled members to more effectively manage their disability and day-today lives. For some members, exercising was also vital to maintain their current health and prevent future decline: "I go because I improve, whereas I should be degenerating... I am [altering] the natural process of my injury and my neurologist is amazed at my ability to maintain my level.” (Member 10). For others, the psychological benefit of achieving personally meaningful goals facilitated continued involvement in the program:

So one year ago I didn't really go out of the house. When I did I was with my husband, so I wasn't driving, he did all of the picking up the kids and everything. I was really borderline depression, because I was feeling really like I saw myself declining in a really rapid way. So, now I'm you know doing my shopping, I'm sometimes picking up my kids... I still don't have the energy, it's not like wow now I'm cured or anything like that, but I still have to decide how I'm going to spend my energy in a day, but I'm definitely doing a lot more and my whole outlook is much more positive. (Member 13)

Interestingly, participation in Revved Up was also meaningful for the program providers in a variety of ways. For example, playing a role in designing and implementing the program was meaningful in terms of feeling a sense of responsibility to others. Many providers stated that the most rewarding aspect of their job was being able to see the positive impact they had on the lives of program members: "There's one participant who will always tell me how much Revved Up has changed her life and that she would be lying on the couch without it and that's the most rewarding thing (Supervisor 2)”. Additionally, the experience of participating in Revved Up was personally meaningful in the providers' own lives: 


\section{FOSTERING QUALITY EXPERIENCES}

And we've learned so much from the process, like it has impacted what I want to do with my life too which is kind of interesting and you form such special relationships with them [program members] I find that it is one of the highlights of my week. Every week when I come home from Revved Up, I just feel better than I did before I went. I am so grateful for the participants, they're so lovely and they're so kind and you learn so much from them. (Supervisor 5) 


\section{FOSTERING QUALITY EXPERIENCES}

\section{Discussion}

The purposes of this study were to explore participation experiences of adults with physical disabilities in a community-based exercise program from two perspectives, and to establish whether the participants' experiences could be understood through Martin Ginis and colleagues ${ }^{13}$ quality participation framework. Participation experiences encompassed autonomy, belongingness, challenge, engagement, mastery and meaning, suggesting that Martin Ginis and colleagues ${ }^{13}$ conceptualization of quality participation can be applied in a community-based exercise program setting. Notably, findings extend those of Shirazipour, and colleagues ${ }^{2}$ by identifying aspects of the quality participation framework besides autonomy, belongingness and mastery that can be targeted in a community-based exercise program for persons with physical disabilities.

Findings from the current study begin to fill a gap in the literature by uncovering preliminary mechanisms for how quality experiences can be fostered in community-based exercise programs for persons with disabilities. Based on program member and provider perspectives, several strategies for fostering the six aspects of quality participation in this setting were identified (Table 1). While several of these strategies have been previously reported $^{2,16}$, the strategies suggested for fostering engagement and meaning are novel contributions to the literature.

Although the experience of enjoyment was evident in our data, we interpreted that it was related to, or an outcome of, other aspects such as belongingness (e.g., it was fun because people were exercising with their peers) and engagement (e.g., it was enjoyable because members and providers share a positive outlook towards the program) rather than as a separate aspect of quality participation. We agree with comments from Martin Ginis and colleagues ${ }^{13}$ that the underpinning role of affect and emotion in quality participation needs 


\section{FOSTERING QUALITY EXPERIENCES}

further exploration. Further research is also required to determine the antecedents and outcomes of quality participation, and how outcomes influence future participation.

Results have been presented to highlight the individual six aspects of quality participation; however, during the analysis, it was challenging to separate the interrelatedness between them. As previously reported ${ }^{16}$, experiencing an initial aspect can lead to the outcome of experiencing subsequent aspects, bolstering overall quality experience. For example, in the present study there was an interaction between autonomy, mastery and meaning; that is, achievements such as increased strength and endurance (mastery) lead to the attainment of personal goals (meaning) such as maintaining functional independence (autonomy) outside of the program. Similar relationships between participation experiences and outcomes have been noted in previous qualitative research in community-based exercise programs ${ }^{10}$. Furthermore, in the present study, belongingness and engagement were closely related aspects of participation, as the social aspect of the program influenced engagement during the exercise sessions, as well as long-term commitment. Therefore, efforts were made to demonstrate how belongingness was experienced in terms of the group aspect of the program and volunteer-member relationships, whereas engagement emphasised how the group structure and one-on-one partnerships impacted members' motivation. Given a proximal aspect (e.g., belongingness) may mediate the experience of a more distal aspect (e.g., mastery, meaning ${ }^{16}$, identifying connections between strategies targeting aspects and the aspects themselves is warranted, specifically using a longitudinal design or integrated qualitative methods ${ }^{20}$. Understanding these relationships would help researchers identify strategies for optimizing quality experiences within community-based exercise programs for persons with physical disabilities.

While this study did not explicitly focus on the quality experiences of program providers, findings suggest that Martin Ginis and colleagues ${ }^{13}$ conceptualization of 


\section{FOSTERING QUALITY EXPERIENCES}

participation has the potential to be applied in a community-based exercise program beyond program members (i.e., persons with a disability). In line with previous research ${ }^{2}$, providers helped foster quality experiences of members; specifically, volunteers were integral to members' experience of belongingness and engagement, and trainers were integral to members' experience of challenge and mastery. However, a novel finding of this study is that providers, themselves, can also experience aspects of quality participation. In particular, providers reported experiencing meaning through their participation in Revved Up; that is, they felt a sense of responsibility to members, saw meaning in the positive impact the program had on members' lives, and learned from members in a way that shaped their future life path. An avenue for future research is to explore the quality experiences of providers to determine whether all aspects of the quality participation framework are experienced and how provider experiences interact with the experiences of members with a disability; that is, providers who have quality experiences might be more likely to foster quality experiences among members. Thus, strategies to optimize quality experiences of program providers may also indirectly foster quality experiences among program members.

\section{Limitations}

The study is not without limitations. First, the findings represent participation experiences of adults with physical disabilities within one community-based exercise program; future research should examine the generalizability of our findings in other programs $^{21}$. Second, the majority of program member participants were male, whereas the majority of program provider participants were female; thus, not all genders were equally represented among both groups in our study and perceptions of how programs can foster quality experiences may differ between men and women. As there is a paucity of research regarding gender differences in quality participation experiences, it is hard to say how unequal gender representation may have influenced the results. However, program members 


\section{FOSTERING QUALITY EXPERIENCES}

and program providers commented on similar on key aspects of participation (i.e., challenging exercise programs, exercising with peers), suggesting that quality experiences may not be moderated by gender. Additional research exploring gender differences in quality participation experiences is warranted.

\section{Conclusion}

Experiencing autonomy, belongingness, challenge, engagement, mastery, and meaning are important aspects of participation in a community-based exercise program for adults with physical disabilities, supporting the use of Martin Ginis and colleagues ${ }^{13}$ quality participation framework within this context. Many of the six elements of quality participation were interrelated; future research is needed to better understand these relationships. Several strategies were identified for fostering quality participation within community-based programs. Study findings provide initial recommendations for (1) practitioners (i.e., program providers) designing and implementing exercise programs for persons with physical disabilities that optimize full and effective participation, and (2) researchers evaluating what constitutes a quality program and why participation outcomes are optimized. 


\section{FOSTERING QUALITY EXPERIENCES}

\section{Acknowledgements}

The authors would like to acknowledge Nicole Giouridis for assistance with manuscript formatting, Jessica Holloway for her assistance with focus group transcription, and the Revved Up program members and providers for contributing their time to this research study. 


\section{FOSTERING QUALITY EXPERIENCES}

\section{References}

1. World Health Organization. International Classification of Functioning, Disability, and Health.; 2001. doi:10.1055/s-0033-1338283

2. Shirazipour, C. H., Evans, M. B., Leo, J., Lithopoulos, A., Ginis, K. A., \& LatimerCheung AE. A systematic review of quality participation context characteristics in community-based physical activity programs for people with physical disabilities. Disabil Rehabil.

3. Dijkers MP. Issues in the conceptualization and measurement of participation: An overview. Arch Phys Med Rehabil. 2010;91(9 SUPPL.).

doi:10.1016/j.apmr.2009.10.036

4. The United Nations. Convention on the Rights of Persons with Disabilities. Treaty Ser. 2006;2515:3. https://www.un.org/development/desa/disabilities/convention-on-therights-of-persons-with-disabilities/article-30-participation-in-cultural-life-recreationleisure-and-sport.html.

5. Statistics Canada. Participation and Activity Limitation Survey. Ottawa, Ontario; 2001.

6. Craig C, Cameron C. Increasing physical activity assessing trends from 1998-2003. Can Fit Lifestyle Res Inst. 2004.

7. Martin Ginis KA, Ma JK, Latimer-Cheung AE, Rimmer JH. A systematic review of review articles addressing factors related to physical activity participation among children and adults with physical disabilities. Health Psychol Rev. 2016;10(4):478494. doi:10.1080/17437199.2016.1198240

8. Martin Ginis KA, Hicks AL. Considerations for the development of a physical activity guide for Canadians with physical disabilities. Appl Physiol Nutr Metab. 2007;32(2):S135-47. doi:https://doi.org/10.1139/H07-108

9. Crawford A, Hollingsworth HH, Morgan K, Gray DB. People with mobility 
FOSTERING QUALITY EXPERIENCES

impairments: Physical activity and quality of participation. Disabil Health J. 2008;1(1):7-13. doi:10.1016/j.dhjo.2007.11.004

10. Adam SL, Morgan KA. Meaningful components of a community-based exercise program for individuals with disabilities: A qualitative study. Disabil Health J. 2018;11(2):301-305. doi:10.1016/j.dhjo.2017.09.001

11. Shirazipour CH, Evans MB, Caddick N, et al. Quality participation experiences in the physical activity domain: Perspectives of veterans with a physical disability. Psychol Sport Exerc. 2017;29:40-50. doi:10.1016/j.psychsport.2016.11.007

12. Imms C, Granlund M. Participation: Are we there yet. Aust Occup Ther J. 2014;61(5):291-292. doi:10.1111/1440-1630.12166

13. Martin Ginis KA, Evans MB, Mortenson W Ben, Noreau L. Broadening the Conceptualization of Participation of Persons With Physical Disabilities: A Configurative Review and Recommendations. Arch Phys Med Rehabil. 2017;98(2):395-402. doi:10.1016/j.apmr.2016.04.017

14. Allan V, Smith B, Côté J, Martin Ginis K, Latimer-Cheung A. Narratives of participation among individuals with physical disabilities: A life-course analysis of athletes' experiences and development in parasport. Psychol Sport Exerc. 2018;37:170-178. doi:doi: 10.1016/j.psychsport.2017.10.004

15. Evans MB, Shirazipour $\mathrm{CH}$, Allan V, et al. Integrating insights from the parasport community to understand optimal Experiences: The Quality Parasport Participation Framework. Psychol Sport Exerc. 2018;37:79-90. doi:10.1016/j.psychsport.2018.04.009

16. Shirazipour, C. H., Aiken, A. B., \& Latimer-Cheung AE. Exploring strategies used to deliver physical activity experiences to Veterans with a physical disability. Disabil Rehabil. 2017:1-8. doi:10.1080/09638288.2017.1377297 


\section{FOSTERING QUALITY EXPERIENCES}

17. Sparkes AC, Smith B. Qualitative Research Methods in Sport Exercise and Health: From Process to Product.; 2014. doi:10.4324/9780203852187

18. Braun, V., Clarke, V., \& Weate P. Using thematic analysis in sport and exercise research. In: International Handbook of Qualitative Methods in Sport and Exercise. London: Routledge; 2016:274-288.

19. Smith B, McGannon KR. Developing rigor in qualitative research: problems and opportunities within sport and exercise psychology. Int Rev Sport Exerc Psychol. 2017;11(1):101-121. doi:10.1080/1750984X.2017.1317357

20. Williams TL. Exploring narratives of physical activity and disability over time: A novel integrated qualitative methods approach. Psychol Sport Exerc. 2017;37:224-234. doi:10.1016/j.psychsport.2017.09.004

21. Smith B. Generalizability in qualitative research: misunderstandings, opportunities and recommendations for the sport and exercise sciences. Qual Res Sport Exerc Heal. 2018;10(1):137-149. doi:10.1080/2159676X.2017.1393221 